\title{
Coulisses
}

Revue de théâtre

15 | Hiver 1997

Varia

\section{Méditation après la représentation de L'Annonce faite à Marie}

Jacques Chevalier

\section{(2) OpenEdition}

Journals

Édition électronique

URL : http://journals.openedition.org/coulisses/5087

DOI : $10.4000 /$ coulisses.5087

ISSN : 2546-9460

Éditeur

Presses universitaires de Franche-Comté

\section{Édition imprimée}

Date de publication : 1 janvier 1997

Pagination : 45-46

ISSN : 1150-594X

\section{Référence électronique}

Jacques Chevalier, « Méditation après la représentation de L'Annonce faite à Marie », Coulisses [En ligne], 15 | Hiver 1997, mis en ligne le 26 avril 2019, consulté le 31 octobre 2019. URL : http:// journals.openedition.org/coulisses/5087 ; DOI : 10.4000/coulisses.5087

Ce document a été généré automatiquement le 31 octobre 2019.

Coulisses 


\title{
Méditation après la représentation de L'Annonce faite à Marie
}

\author{
Jacques Chevalier
}

1 La Cathédrale Saint-Jean de Besançon a servi de cadre à deux représentations de L'Annonce faite à Marie de Paul Claudel, par les comédiens des Nuits de Joux qui, sous la direction de Pierre Louis, reprennent ainsi leur création de juillet 1995 au château de Joux. Ayant conservé le lointain souvenir d'une représentation du Soulier de satin, à laquelle j'avais assisté il y a une trentaine d'années et qui m'avait paru longue et ennuyeuse, je souhaitais, mais toutefois avec une certaine appréhension, connaître cette pièce la plus jouée de Claudel, L'Annonce faite à Marie.

\section{Une mise en scène initiatrice}

2 Dès la coupure marquant la fin du premier acte, la pièce m'a paru d'un accès facile, et cela en dépit des références religieuses de l'œuvre et malgré le style de Claudel, souvent déroutant au premier abord.

Le drame - mystère en quatre actes et un prologue - se déroule dans le cadre d'une France paysanne et moyenâgeuse, où retentit l'écho de la guerre de Cent Ans et des désordres religieux de cette époque, liés à l'exil de la papauté à Avignon. Claudel fait appel à des valeurs de toujours. Il décrit l'attachement à la terre : «Voici trente ans que je tiens ce fief sacré de mon père", exalte le travail: "votre domaine, cet océan de sillons, jusques au bout de la France, il n'a pas démérité entre mes mains». Mais surtout, les personnages de Claudel nous paraissent très proches et vrais dans la simplicité de leurs réactions. Ainsi en est-il de la scène du premier acte entre la mère et Anne Vercors, qui revêt un aspect de discussion domestique presque banal. Tout au long de la pièce vont s'exprimer des passions dans lesquelles nous pouvons nous reconnaître. Qui serait insensible à l'humanité du personnage de Mara, mère torturée et pourtant toujours qualifiée de méchante, prête à tous les sacrifices pour que revive l'enfant qu'elle vient de perdre : «Rends-moi cet enfant que je t'ai donné. Eh bien, je m'humilie, aie pitié de moi ! » 


\section{Un texte porteur de foi}

Rebutante à la première lecture ou à la première audition, l'écriture de Claudel, originale par sa forme, parfois proche du vers, mais sans rime, n'en est pas moins claire, s'exprimant souvent en des formules parées de pittoresque : «Et l'autre (le roi) si petit qu'on ne le voit plus entre les roseaux de la Loire», de réalisme : «ne reproche pas cette lumière à la créature calcinée ", ou de poésie : "Ô ma fiancée à travers les branches en fleurs ».

Récit d'un amour contrarié, drame de la jalousie entre deux sœurs, la pièce de Claudel, qui nous paraît à cet égard si proche, s'élève aussi vers le spirituel et le merveilleux, à travers les personnages de Violaine et de son père, dont le cheminement intérieur reflète la pensée religieuse de l'auteur.

«Tout périt et je suis épargné »: c'est la profession de foi par laquelle Anne Vercors justifie auprès de sa femme son départ pour Jérusalem. Dieu lui a accordé le bonheur et la prospérité, mais il ne peut pas accepter cette situation, car d'autres souffrent. Aussi, une autre mission l'appelle maintenant: se joindre aux pèlerins qui l'entraînent et le poussent, guidés par la main de Dieu. Comme son père, mais beaucoup plus tôt dans sa vie, Violaine a reçu le message du ciel, symbolisé par la maladie que lui a transmise le baiser donné à Pierre de Craon. Elle a compris l'appel et annonce à Jacques Hury, son fiancé, qu'elle ne pourra pas l'épouser : « La main de Dieu est sur moi et tu ne peux me défendre ». À l'acte suivant, elle précise à sa sœur Mara l'étendue de la mission qui lui est assignée, souffrir en rachat des malheurs du temps : «C'est pourquoi voici mon corps en travail à la place de la chrétienté qui se dissout». Violaine, qui souffre et supplie, se défend d'être une sainte, refuse de succomber au péché d'orgueil et ne prétend à aucune récompense pour elle-même.

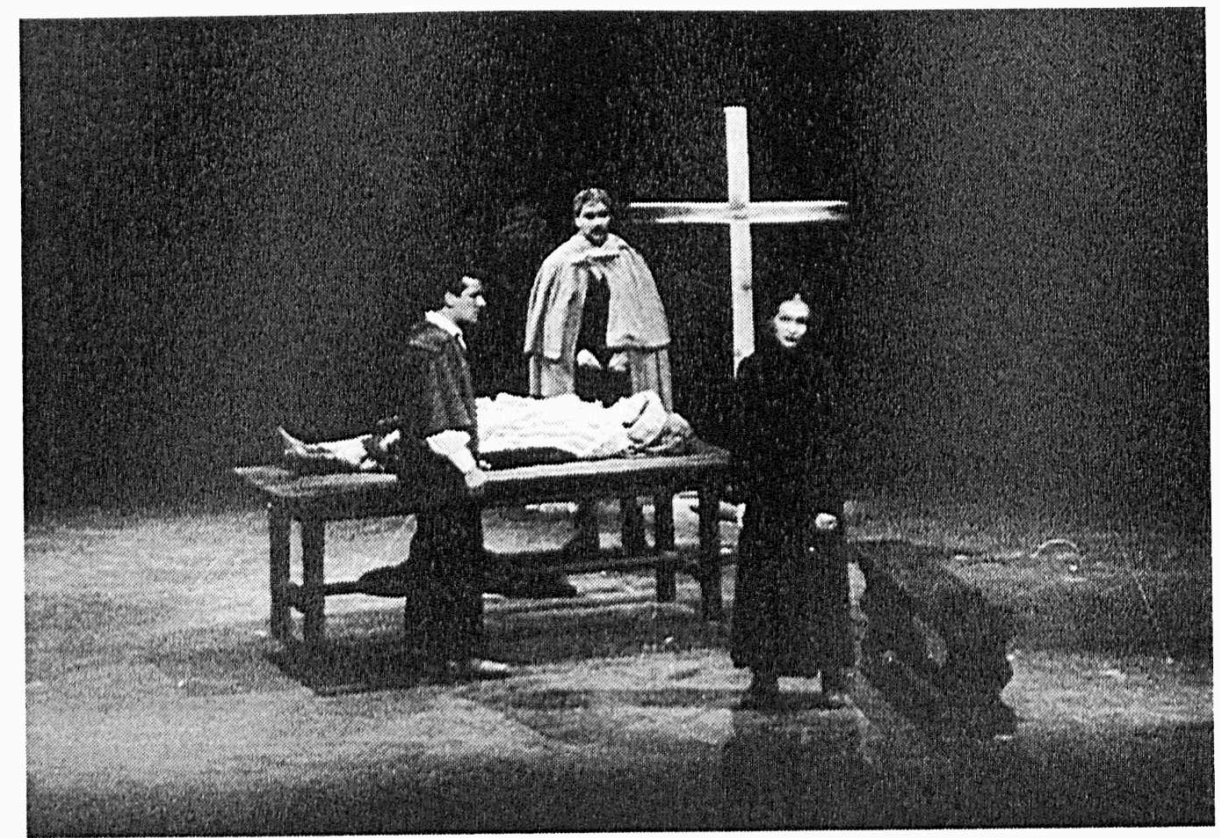

Cliché CAHD 
Pourtant, sa confiance absolue en Dieu l'a convaincue que sa souffrance n'était pas vraiment subie: "Puissante est la souffrance quand elle est aussi volontaire que le péché ». C'est cette puissance de la souffrance qui peut expliquer, il me semble, la résurrection de l'enfant de Mara, qui dans la démarche claudélienne, est le fruit de la mission pleinement assumée par Violaine : Souffrance et renoncement, sans espoir de récompense terrestre pour elle-même.

5 L'intervention du surnaturel dans la pièce de Claudel lui confère - c'est une évidence un caractère d'irréalité auquel il est permis de ne pas adhérer. Pourtant, rejeter dans Claudel tout ce qui procède du religieux, serait méconnaître quelques-uns des aspects les plus intéressants de l'œuvre. L'élévation de pensée de Violaine et de son père, capables de renoncement et de sacrifice, doit être considérée comme un acte de foi en l'homme, car même si leur comportement est sous-tendu par des convictions religieuses, ces personnages restent des créatures pleines d'humanité, souffrant dans leur chair - pour Violaine - et dans leur esprit. Tout homme dispose des moyens de participer, même modestement, à l'élaboration d'une œuvre commune : c'est encore l'un des messages délivrés par Claudel, qui exprime, là encore, sa foi en l'homme, par la bouche de l'apprenti de Pierre de Craon, à la scène 1 de l'acte III.

\section{Une interprétation sans mystère}

6 L'interprétation de L'Annonce faite à Marie à la cathédrale Saint Jean m'a dans l'ensemble satisfait. Cependant, je n'ai jamais ressenti de véritable émotion pendant la longue scène de l'acte III entre Violaine et Mara. Certes, je n'admets pas le miracle, mais il me semble qu'une actrice convaincante dans le rôle de Violaine devrait, par son jeu, au moins le temps de la représentation, forcer le spectateur à admettre l'intervention du merveilleux. Je n'ai pas beaucoup aimé le jeu de l'acteur tenant le rôle du père; Anne Vercors nous apparaît comme un illuminé, quittant sa famille et sa terre sans regret (c'est du moins ce que j'ai ressenti). Or il me semble que son départ, tout en étant volontaire, devrait nous apparaître comme un déchirement.

Je n'ai pas de compétence pour émettre une critique sur la mise en scène; je ne peux que livrer des impressions. La représentation de L'Annonce faite à Marie me parait tout naturellement trouver sa place dans une église; les mystères n'étaient-ils pas représentés sur le parvis des cathédrales? Je pense que le contre-chœur de la cathédrale Saint Jean aurait dû être utilisé en totalité. Malheureusement, il nous apparaît comme coupé et en partie dissimulé par la tringle supportant le rideau devant lequel évoluaient les acteurs. Ainsi, en partie gommée, la solennité du lieu ne renforçait pas, autant qu'elle aurait pu le faire, la capacité d'émotion du drame de Claudel. 


\section{AUTEURS}

JACQUES CHEVALIER

Auditeur de l'Université Ouverte 